Józef Stala

The Pontifical University of John Paul II in Krakow, Poland

\title{
Geistig behinderte Kinder religiös erziehen - Herausforderungen an Pädagogik und Katechese
}

\section{Religious Upbringing of a Child with Intellectual Disability - Pedagogical and Catechetical Challenges}

\begin{abstract}
Special education options are diverse and prepared to meet the needs of children with varying degrees of intellectual disabilities. However, many parents of children with an intellectual disability have a difficult time in organizing the religious educational alternatives for their children. A disabled child needs to be surrounded by catechetical specialist care. In this article, the author points out the pedagogical and catechetical challenges of special education and catechesis. At the beginning, three basic educational environments are presented followed by the major aspects of the Catholic religious education: knowledge of God, prayer, and preparation for the sacrament of Penance and the Eucharist
\end{abstract}

\section{Keywords}

Religious upbringing, intellectual disability, pedagogical environments, catechesis.

Das behinderte Kind muss mit einer besonderen katechetischen Fürsorge umgeben werden. Die Sonderkatechese ist analog zur Sonderpädagogik die Lehre davon, wie man Menschen mit wie auch immer gearteter geistiger oder körperlicher Beeinträchtigung religiös erziehen und bilden kann. Der Ausgangspunkt für diese spezielle Form der Katechese besteht darin, ihre Adressaten als Subjekte zu behandeln, als Personen, die auf unterschiedliche Art und Weise behindert sind und aufgrund von Verletzung, Krankheit oder angeborener Behinderung erhebliche Schwierigkeiten haben oder nicht in der Lage sind Dinge auszuführen, die für Gleichaltrige gewöhnlich keinerlei Problem darstellen. 
Das geistig behinderte Kind begegnet Gott im Taufsakrament, in dem es die Gnade des Glaubens empfängt, es glaubt an Gott und es glaubt Gott, dass alles, was Gott offenbart, die Wahrheit ist. In der „Erklärung über die christliche Erziehung” des Zweiten Vatikanischen Konzils lesen wir: „Alle Christen, die, durch die Wiedergeburt aus dem Wasser und dem Heiligen Geist zu einer neuen Schöpfung geworden, Söhne Gottes heißen und es auch sind, haben das Recht auf eine christliche Erziehung"'. Das geistig behinderte Kind stellt die den Gläubigen einmal übergebene Glaubenswahrheit nicht in Frage, es vertraut Gott grenzenlos, es ist offen für die geistige Ebene und kann mit seiner Liebe auf die Liebe Gottes antworten. Man muss ihm nur dabei helfen und es lehren, in dieser Wirklichkeit zu leben ${ }^{2}$. Darum erscheint es als überaus bedeutsam, auf die pädagogischen und katechetischen Herausforderungen zu verweisen, die bei der religiösen Erziehung eines Kindes mit kognitiven Einschränkungen auftreten. Dazu werden zunächst drei grundlegende Erziehungsumgebungen vorgestellt. Im Anschluss daran wird erörtert, wie das geistig behinderte Kind in das religiöse Leben eingeführt werden kann, indem es Gott kennen lernen darf, in das Gebetsleben eingeführt sowie auf den Empfang des Bußsakraments und der Heiligen Kommunion vorbereitet wird.

\section{Drei Erziehungsumgebungen des geistig behinderten Kindes}

In der Erziehung allgemein, insbesondere auch in der Religionserziehung, spielen die sich wechselseitig ergänzenden und durchdringenden drei grundlegenden Erziehungsumfelder die bedeutendste Rolle: das familiäre Heim, die Schule und die Pfarrgemeinde. Im Falle der geistig behinderten Kinder sehen diese so aus: das familiäre Heim, die Förderschule und die

1 Gravissimum educationis 2.

2 Vgl. B. Rozen, Edukacja religijna osób z niepelnosprawnościa intelektualna. Studium pedagogiczno-religijne, Olsztyn 2008; A. Kiciński, Katecheza osób z niepetnosprawnościa intelektualna, Lublin 2007; A. Żyta, Edukacja osób z gtębsza niepetnosprawnościa intelektualna w Polsce - przeszłość, teraźniejszość i przyszłość, in: Wielowymiarowość edukacji osób z niepetnosprawnościa, Hrsg. C. Kosakowski, C. Rogowski, Olsztyn 2005, S. 169-175; J. Stala, Katecheza specjalna wyrazem troski o każdego człowieka $w$ świetle dokumentów synodalnych Kościoła w Polsce po 1980 roku, in: Katecheza specjalna dzisiaj. Problemy i wyzwania, Hrsg. J. Stala, Kielce 2003, S. 55-66; J. Wyczesany, Pedagogika upośledzonych umysłowo, Kraków 1999; A. Nowak, Katechizacja dzieci specjalnej troski, „Katecheta” 41 (1997) Nr. 3, S. 148-150; H. Koselak, Wychowanie religijne osób niepetnosprawnych umystowo, „Horyzonty Wiary” (1993), S. 66-75. 
Gemeinschaft der Pfarrei ${ }^{3}$. Alle drei genannten Umgebungen beeinflussen, jede für sich wie auch gemeinsam, durch konkretes und jeweils spezifisches Wirken das Entstehen, die Entwicklung und die Festigung des Glaubens bei einem Kind mit kognitiven Einschränkungen:

a/ Das familiäre Heim - es ist der natürliche Ort, um unmittelbar in das religiöse Leben eingeführt zu werden. Sind es doch zunächst die Eltern, die als erste Erzieher die religiösen Grundhaltungen formen, denn „die Familienkatechese geht daher jeder anderen Form der Katechese voraus, begleitet und bereichert sie"4. Die religiöse Erziehung besteht in der Hinführung darauf, Gott kennen zu lernen sowie mit dem Gebetsleben und der Liturgie der Kirche vertraut zu werden. Die Eltern von Kindern mit geistiger Behinderung treten nicht selten mit Befürchtungen und Vorbehalten an die Religionserziehung ihrer Kinder heran. Deshalb ist es von besonderer Bedeutung, sie dabei zu unterstützen und sie auf diesem Weg durch Offenheit für ihre Fragen und Probleme zu begleiten ${ }^{5}$. Die Eltern, die ein Kind mit kognitiven Einschränkungen erziehen, sollen sich nicht nur um die Rehabilitation und die Gesundheit ihres Kindes sondern auch um dessen religiöse Erziehung kümmern. Hierbei nimmt das Beispiel der Eltern, Großeltern, der Verwandten und der näheren Bezugspersonen eine Rolle

3 Vgl. J. Stala, Rodzina wobec niepetnosprawności intelektualnej dziecka. Obawy i nadzieje, in: Etyczne i duchowe potrzeby osób niepetnosprawnych, Hrsg. R. Buchta, K. Sosna, Katowice 2007, S. 30-39; J. Stala, D. Jucha, Katechizacja osób upośledzonych umystowo, in: Katechetyka szczególowa, Hrsg. J. Stala, Tarnów 2003, S. 316-317; D. Kornas-Biela, Osoba niepetnosprawna i jej miejsce w społeczeństwie, Lublin 1988.

4 Catechesi tradendae 68.

5 Vgl. Podstawa programowa katechezy Kościoła katolickiego w Polsce, S. 111; J. Kielin, Rodzic - partner czy intruz, „Bardziej Kochani” (2004) Nr. 2, S. 10-14; Z. Kazanowski, Środowisko rodzinne młodzieży niepetnosprawnej intelektualnie w stopniu lekkim, Lublin 2003; A. M. Kielar, Kiedy w rodzinie przychodzi na świat dziecko niepetnosprawne, „Oligokatecheza” 1 (2003) Nr. 2, S. 6-12; J. Grochowska, Rodzice i rodzeństwo osób autystycznych, „Światło i cienie" (2001) Nr. 3, S. 26-30; T. Serafin, Poradnik dla rodziców niepetnosprawnego dziecka, „Bardziej Kochani” (2001) Nr. 2, S. 2-10; B. Sidor, Trudności przeżywane przez rodzinę dziecka $z$ niepetnosprawnościa umystowa, in: Rodzina: źródto życia i szkoła miłości, Hrsg. D. KornasBiela, Lublin 2000, S. 393-405; E. Muszyńska, Dziadkowie $w$ rodzinie z niepetnosprawnym dzieckiem, „Światło i Cienie” (1998) Nr. 3, S. 6-9; E. Pisula, Psychologiczne problemy rodziców dzieci z zaburzeniami rozwoju, Warszawa 1998; H. Borzyszkowska, Izolacja społeczna rodzin majacych dziecko upośledzone umysłowo w stopniu lekkim, Gdańsk 1997; M. Kruk, Relacje między rodzeństwem zdrowym i niepetnosprawnym $w$ rodzinie, „Światło i Cienie” (1996) Nr. 2, S. 4-8; P. Poręba, Rodzina chrześcijańska „małym Kościołem”, in: Wychowanie w rodzinie, Hrsg. F. Adamski, Kraków 1991, S. 99-101; F. Wojciechowski, Dziecko upośledzone w rodzinie, Warszawa 1990; A. Twardowski, Sytuacja rodzin dzieci niepetnosprawnych, Warszawa 1987. 
von immenser Bedeutung ein - das gemeinsame Gebet, die gemeinsame Teilnahme an Katechesen, an Begegnungen, an der Sonntagsmesse und an weiteren Gottesdiensten.

b/Diespeziellenschulischen/pädagogischenZentren, dieFörderschulenund die Häuser mit sozialer Unterstützung - hier wird die Religionsunterweisung von Priestern, Ordensschwestern und Laienkatecheten durchgeführt, die spezifisch und adäquat darauf vorbereitet sind, die also die Qualifikation für den Religionsunterricht an Förderzentren erworben haben. Leider nehmen die Eltern der Kinder nur selten an den Katechesen teil, was den Erfolg des katechetischen Einwirkens auf die geistig behinderten Kinder etwas schmälert. Denn die Religionserziehung sollte durch die Teilhabe und die Mitwirkung der Eltern erfolgen, weil sich die Kinder gerne ihrer Pflichten entledigen, wenn die Eltern nicht anwesend sind ${ }^{6}$.

c/ Die Pfarrgemeinde - sie soll die Katechesen inspirieren und übernimmt diese Aufgabe auch tatsächlich7. Die Pfarrei ist der Ort, an dem jeder, insbesondere das geistig behinderte Kind, Hilfestellung findet, um sein religiöses Leben zu beginnen und weiter zu entfalten. Die Pfarrgemeinde unterstützt die Eltern und Pfleger bei der Religionserziehung, bei der Vorbereitung auf den Empfang der Sakramente und bei der speziellen Seelsorge für Kinder mit kognitiven Einschränkungen. Als Initiative sollten die Seelsorger und die Eltern von geistig behinderten Kindern vor allem zusammen mit größeren Pfarrgemeinschaften Gruppen bilden, in denen sich Familien mit betroffenen Mitgliedern verbinden. Derartige Selbsthilfegruppen können dazu beitragen, die Organisation und die Teilnahme an der H1. Messe und der Katechese zu erleichtern, welche ein Teil der Homilie ist oder unmittelbar nach der Messfeier stattfindet. Die Katechese von Kindern mit kognitiven Einschränkungen hilft dabei, diese so weit wie möglich auf eine umfassende Beteiligung am kirchlichen Leben vorzubereiten, damit sie an den Gottesdiensten teilnehmen und die Sakramente empfangen können. Wenn dem geistig behinderten Kind die Rahmenbedingungen und die Möglichkeiten geschaffen werden, sich in das Leben der Pfarrgemeinde einzubringen, dann gibt ihm dies die Chance in

6 Vgl.Edukacja uczniów z głębszym upośledzeniem umysłowym. Przewodnik dla nauczycieli, Hrsg. M. Orkisz, M. Piszczek, A. Smyczek, J. Szwiec, Warszawa 2000; M. Bojnowska, Katecheza dzieci upośledzonych umysłowo w systemie szkolnictwa specjalnego, „Katecheta” 35 (1991) Nr. 3, S. 166.

7 Vgl. Gravissimum educationis 3; Catechesi tradendae 67. 
der Gemeinschaft der Gläubigen zu leben und sich mit ihr zu identifizieren. So kann es auch seine eigenen Grundhaltungen und religiösen Erlebnisse besser ausdrücken ${ }^{8}$. In der speziell auf Menschen mit Behinderung ausgerichteten Katechese erfüllt die Pfarrgemeinde eine zweifache Aufgabe: Sie organisiert Katechesegruppen für die geistig behinderten Kinder und informiert die Pfarrangehörigen, dass es in der Pfarrei Familien mit geistig behinderten Angehörigen gibt. Damit kann diesen die Teilnahme an der Hl. Messe, der Zugang zu den Sakramenten und eine Katechese ohne Angst vor unangebrachtem Verhalten ermöglicht werden.

\section{Das geistig behinderte Kind wird in das religiöse Leben eingeführt}

Bei der Religionserziehung des geistig behinderten Kindes ist es wichtig, ihm das Bild des liebenden Gottes bewusst zu machen, der sich um es kümmert und ihm ein Gefühl von Sicherheit verleiht, ihm aber auch die spezifischen Verhaltensmuster und Haltungen gegenüber seiner Umgebung $\mathrm{zu}$ vermitteln. Die religiöse Entwicklung des Kindes mit kognitiven Einschränkungen verläuft nicht geradlinig, was bedeutet, dass nach dem gegebenen Entwicklungsstadium nicht notwendigerweise ein höheres folgen muss, dass es vielleicht sogar zurück fällt - dauerhaft oder nur zeitweise ${ }^{9}$. Um die Aufgabe möglichst gut zu erfüllen, ist es erforderlich, dass sich bei der Religionserziehung des geistig behinderten Kindes vor allem die Eltern und die nähere Familie, ebenso aber die Nachbarn und die Pfarrgemeinde

8 Vgl. Podstawa programowa katechezy Kościoła katolickiego w Polsce, S. 112; Etyczne $i$ duchowe potrzeby osób niepetnosprawnych, Hrsg. R. Buchta, K. Sosna, Katowice 2007; A. Wojciechowski, Zrozumieć człowieka w jego najwyższym wymiarze osobowym-jako dziecka Boga, „Oligokatecheza” 2 (2004) Nr. 4, S. 4-13; J. Stala, Katecheza specjalna realizacja Bożego miłosierdzia, „Edukacja. Teologia i Dialog” (2004), T. 1: Miłosierdzie jako wartość w języku współczesnej edukacji, Hrsg. R. Niparko, J. Skrzypczak, S. 189-200; M. Kosacz, Osoby o intelektualnej niepetnosprawności w Kościele i spoleczeństwie, „Katecheta” 45 (2001) Nr. 2, S. 43-48.

9 Vgl. A. Kiciński, Katecheza grup specjalnej troski, „Roczniki Teologiczne” (2003) Nr. 6, S. 121-137; K. i K. Lausch, Stów kilka o wychowaniu religijnym dzieci i młodzieży z głęboka niepetnosprawnościa intelektualna, in: Katecheza specjalna dzisiaj. Problemy i wyzwania, Hrsg. J. Stala, Kielce 2003, S. 169-185; Z. Golan, Kształtowanie się obrazu Boga u dzieci upośledzonych umystowo w stopniu umiarkowanym, „Studia Teologiczne Białystok - Drohiczyn - Łomża” 17 (1999), S. 299. 
engagieren ${ }^{10}$. Deshalb erscheint es nur zu berechtigt, im Folgenden genauer zu erörtern, wie das geistig behinderte Kind Gott kennen lernen kann, wie es in das Gebet eingeführt sowie auf den Empfang des Bußsakraments und der Heiligen Kommunion vorbereitet werden kann.

\subsection{Das Kind lernt Gott kennen}

Damit das geistig behinderte Kind ein richtiges Gottesbild entwickeln kann, ist es von wesentlicher Bedeutung, dass es - vor allem durch seine Eltern - ein Gefühl von Sicherheit, Akzeptanz, Fürsorge (auch wenn ihm Fehler unterlaufen) und grenzenloser Liebe erfährt, die ihm bedingungslos zuteil wird. Denn die ersten und wichtigsten Erzieher sind die Eltern, die durch das enge Band, das sie mit ihrem geistig behinderten Kind verbindet, für dieses zum Vorbild werden, wie es später seine zwischenmenschlichen Beziehungen ausgestalten kann. Dieses Band stellt auch den Beginn seiner zukünftigen Relation zu Gott dar - das Kind überträgt die Eigenschaften, die es bei seinen Eltern wahrnimmt, auf Gott. Eine entscheidende Rolle spielt hierbei der Vater des Kindes, der die erste Vorstellung von Gott, dem himmlischen Vater prägt. Häufig kommt es vor, dass unangenehme Erfahrungen aus der Kindheit, die mit dem Vater in Verbindung stehen, die Quelle für spätere Probleme mit der Religion sind. Das geistig behinderte Kind kann auch auf anthropomorphe Art und Weise Zugang zu Gott finden, indem es sich Gott ähnlich wie einen Menschen vorstellt und Ihm menschliche Gestalt, Eigenschaften und Verhaltensweisen zuschreibt, oder es malt sich Gott wie ein kleines Kind aus, mit dem man sich unterhalten und spielen kann ${ }^{11}$.

Großen Einfluss auf die Entwicklung der religiösen Sphäre des Kindes mit kognitiven Einschränkungen nimmt außerdem seine nächste Umgebung, also das familiäre Heim mit der gesamten Einrichtung und allen Bewohnern. Die Erziehung vollzieht sich durch das Gesamtbild der Situation, die das behinderte Kind beobachtet und an der es Anteil hat. Durch die Observation der Mitbewohner, ihrer gegenseitigen Beziehungen und deren Relation

${ }^{10}$ Vgl. K. M. Lausch, Teoretyczne podstawy katechizacji osób głębiej upośledzonych umystowo, Warszawa 1987, S. 148.

${ }^{11}$ Vgl. Z. Brzezinka, Katecheza specjalna. Katecheza osób w szczególnych sytuacjach, in: Katechetyka szczególowa, Hrsg. J. Stala, Tarnów 2003, S. 293-305; S. Kuczkowski, Psychologia religii, Kraków 1991, S. 76-77; Z. Golan, Ksztattowanie się obrazu Boga u dzieci upośledzonych umystowo w stopniu umiarkowanym, S. 302; J. Stala, D. Jucha, Katechizacja osób upośledzonych umystowo, S. 330. 
$\mathrm{zu}$ sich selbst sowie durch die Wahrnehmung aller Objekte in seinem Interessensbereich, z. B. das Kreuz oder ein an der Wand aufgehängtes Bild, kann es die ersten Verbindungen zur Religion aufbauen ${ }^{12}$.

Für das geistig behinderte Kind sind auch die in der Familie begangenen Feiern, die Abfolge des liturgischen Jahres und der gemeinsame Besuch der Hl. Messe überaus bedeutungsvoll. Die Eltern vollziehen die Hinführung zur Eucharistie zunächst durch die Taufe, dann durch das gemeinsame Gebet in der Familie und durch die weiteren Sakramente, die erste Beichte und die feierliche Erstkommunion ${ }^{13}$. Die dem Fest voraus gehenden Vorbereitungen bringen für das Kind viele typische optische, akustische und sensorische Eindrücke mit sich. Gerade sie ermöglichen es dem Kind, die einzelnen Feste unterscheiden zu können.

Erst wenn das behinderte Kind das Bild des guten und zuverlässigen Gottes in sich trägt, der ihm immer nahe ist, kann man es an religiöse Inhalte heranführen, zu denen Gesten und Symbole, unabdingbares Wissen und regelmäßige religiöse Praxis gehören. Die ersten Ausdrucksformen der Religiosität werden von dem Kind mit kognitiven Einschränkungen sicher nicht in ihrem spezifischen Sinn verstanden sondern werden eher nachgeahmt, wodurch es sich bemüht, den Anderen durch sein Tun möglichst ähnlich zu werden. Erst nach längerer Zeit werden die Gesten und die religiösen Worte mit den entsprechenden Inhalten verknüpft, die sie weitergeben wollen ${ }^{14}$.

Bei der Ausgestaltung des Gottesbildes ist es ebenso hilfreich, dem Kind mit geistiger Behinderung das Schöne dieser unserer Welt zu zeigen, durch die sich Gott dem Menschen zu erkennen gibt. Das Schöne, dessen Wesen Gott entspringt, bewegt uns zum Guten, erlaubt positive Emotionen, belebt den Intellekt, aktiviert und bewirkt Besserung. Wenn das behinderte Kind die Natur als etwas erlebt, das Begeisterung hervorruft, dann können seine

${ }_{12} \mathrm{Vgl}$. H. Wistuba, Wychowanie religijne małego dziecka $w$ rodzinie, in: Wychowanie w rodzinie chrześcijańskiej, S. 202-203; S. Kuczkowski, Psychologia religii, S. 58-59.

${ }_{13}$ Vgl. U. Gebert, Opieka duszpasterska nad ludźmi z głębszym upośledzeniem umystowym. Możliwości i granice, „Horyzonty Wiary” (1991), S. 23-34; K. Nawrotek, Rodzina środowiskiem uświęcenia, in: Wychowanie katolickie w szkole $i$ w domu, Hrsg. E. Mitek, Warszawa 1996, S. 225.

${ }^{14}$ Vgl. K. Sosna, Przygotowanie do Komunii Świętej osób niepetnosprawnych umysłowo w świetle dekretu Quam singulari, in: Eucharystia - pokuta i pojednanie w katechezie, Hrsg. J. Stala, Kielce 2007, S. 235-244; J. Kirenko, M. Parchomiuk, Edukacja i rehabilitacja osób z upośledzeniem umysłowym, Lublin 2006; K. M. Lausch, Teoretyczne podstawy katechizacji osób głębiej upośledzonych umystowo, S. 147; Z. Golan, Kształtowanie się obrazu Boga u dzieci upośledzonych umystowo w stopniu umiarkowanym, S. 304. 
Eltern damit beginnen, von Gott als dem Schöpfer zu sprechen, indem sie biblische Erzählungen benutzen, die seiner intellektuellen Entwicklung entsprechen. Das geistig behinderte Kind verfügt über eine ,ziemlich gut entwickelte Gefühlswelt. Dank der Entfaltung dieser Sphäre kann es zu einem authentischen Glauben und zu einer überaus engen Beziehung zu Gott fähig sein. Hier geht es darum, das Kind gut und umsichtig anzuleiten und ihm alles zugänglich zu machen, was es mit seinem eingeschränkten Verstand aufnehmen kann"15. Dies alles gilt es zu bedenken, wenn man die Religionserziehung des Kindes mit geistiger Behinderung aufnimmt.

\subsection{Das Kind findet Zugang zum Gebet}

Das Gebet ist eine Gnade, die man zum ersten Mal im Sakrament der Taufe empfängt. Der darin grundgelegte Glauben bietet die Möglichkeit und die Basis für weitere Begegnungen mit Gott, die sich im Gespräch mit Ihm ausdrücken werden - im Gebet, dem sichtbaren Effekt der Religionserziehung des geistig behinderten Kindes. Es begleitet das Kind bereits vor der Geburt, wenn die Eltern Gott im gemeinsamen Gebet für das Kind bitten, um eine glückliche Entbindung und um seine gute Erziehung. Wenn es auf die Welt kommt, tritt es in das bestehende Gebet seiner Eltern ein, bis es in der Taufe selbst die Gnade des Gebets erhält ${ }^{16}$.

Das Kind mit kognitiver Einschränkung betet gefühlvoll und tiefgehend. In seinem direkten und reinen Gebet drückt es seine Liebe zu Gott aus, gern nimmt es sich viel Zeit für sein Gebet. Ein geringer Wortschatz hindert es nicht daran, sich mit improvisierten Gesten oder mit Hilfe von bereits bekannten Symbolen und Haltungen an Gott zu wenden. Das behinderte Kind versenkt sich vollständig in das Gebet und nimmt es sehr wichtig. Am Anfang beteiligt es sich am hörbaren Gebet der Eltern, die bei ihm sind, bevor es allmählich beginnt, die Bewegungen und Worte der betenden Eltern nachzuahmen und schließlich versucht selbstständig zu beten. Seine ersten Gebete sind spontane Dankesworte sowie mit seinen eigenen Worten und Haltungen vorgetragenen

${ }^{15}$ W. Przeczewski, Religijne wychowanie dzieci głębiej upośledzonych umystowo, in: Katechetyka, Hrsg. W. Koska, Poznań 1987, S. 145; Vgl. K. Wereszka, Problemy katechezy dzieci $z$ wada stuchu, in: Katecheza specjalna dzisiaj. Problemy $i$ wyzwania, Hrsg. J. Stala, Kielce 2003, S. 418; J. Baran, Specyficzne problemy kształtowania zachowań moralnych uczniów z niektórymi rodzajami niepetnosprawności, in: Struktury pedagogiczne w katechezie, Hrsg. M. Śnieżyński, Kraków 2001, S. 313.

${ }^{16}$ Vgl. W. Przeczewski, Religijne wychowanie dzieci głębiej upośledzonych umystowo, S. 146; H. Wistuba, Wychowanie religijne małego dziecka w rodzinie, S. 208. 
Bitten, erst in einer späteren Phase spricht es auswendig gelernte kurze Gebete, falls es sich diese aneignen kann. Dazu sollten adäquate kleine Kindergebetbücher ausgewählt werden, die den intellektuellen Möglichkeiten des Kindes entsprechen und die mit passenden Bildern versehen sind, um den Inhalt des jeweiligen Gebets veranschaulichen. Man sollte sich ihrer zum Gebet während der Katechese, daheim und in der Kirche bedienen ${ }^{17}$.

\subsection{Das Kind wird auf den Empfang des Bußsakraments und der Heiligen Kommunion vorbereitet}

Den Beginn der Vorbereitung des geistig behinderten Kindes auf den Empfang der heiligen Sakramente gilt es in der Familie zu suchen, wo die Eltern ihren Glauben selbst aktiv leben. Wenn das Kind das Bußsakrament und die Heilige Kommunion empfangen soll, müssen sich die Eltern ganz ausdrücklich mit der wohl durchdachten und begründeten Bitte an den örtlichen Geistlichen wenden, der die entsprechende Vorbereitung ihres Kindes aufnehmen soll. Gleichzeitig müssen sich die Eltern der Verpflichtung bewusst sein, ihren eigenen Glauben und den ihres Kindes stets weiter $\mathrm{zu}$ entwickeln. Die Vorbereitung des Kindes mit kognitiven Beeinträchtigungen muss in enger Zusammenarbeit seiner Eltern mit dem Katecheten stattfinden. Die Eltern sollen sicher sein, dass die Möglichkeit zum fortwährenden und direkten Kontakt mit dem Priester besteht und sie auf dessen Hilfe zählen können. Diese Zusammenarbeit umfasst für gewöhnlich zwei Formen des Kontakts - sie nehmen zusammen mit ihrem Kind an den Katechesestunden teil und führen ein „Arbeitsheft” zur Religion, das nicht für das Kind sondern für sie selbst bestimmt ist. Darin klebt der Katechet jeweils eine Karte mit den Leitgedanken für den entsprechenden Monat ein, um die Eltern so zu ermuntern, beständig an der Vertiefung ihres eigenen Glaubens zu arbeiten ${ }^{18}$.

${ }^{17}$ Vgl. J. Stala, D. Jucha, Katechizacja osób upośledzonych umysłowo, S. 330; A. Kotlarski, Duszpasterstwo dzieci specjalnej troski. Pierwszy kontakt duszpasterza z dzieckiem upośledzonym, S. 92; W. Przeczewski, Religijne wychowanie dzieci głębiej upośledzonych umysłowo, S. 146; H. Koselak, Przygotowanie osób specjalnej troski do sakramentu pojednania i Eucharystii, „Collectanea Theologica” 57 (1987) Fasc. I, S. 100.

${ }^{18}$ Vgl. K. i K. Lausch, Stów kilka o wychowaniu religijnym dzieci i młodzieży z głęboka niepetnosprawnościa intelektualna, in: Katecheza specjalna dzisiaj, S. 183; K. Lausch, Wychowanie religijne dzieci z niepetnosprawnościa intelektualna $w$ stopniu głębokim oraz ich przygotowanie do przyjęcia sakramentów świętych, „Oligokatecheza” 1(3)/ (2004), S. 17; K. M. Lausch, Katecheza przedkomunijna osób głębiej upośledzonych umystowo, Warszawa 1990, S. 23-24. 
Indem die Eltern und Pfleger Unterstützung bei der Katechese und durch den Katecheten annehmen, beteiligen sie sich aktiv an der Vorbereitung ihres geistig behinderten Kindes auf die Erstkommunion. Häufig zeigt sich das Kind bei den Treffen anfangs misstrauisch, schüchtern und verschlossen, deswegen ist die Anwesenheit einer vertrauten Person sehr hilfreich, mehrfach wird die Aufnahme der Beschäftigung dadurch überhaupt erst ermöglicht. Die Eltern sind über die Inhalte der Katechese informiert, führen Aufzeichnungen, skizzieren die Zeichnungen mit und notieren die Empfehlungen für die weitere Arbeit daheim. Daneben wiederholen sie die behandelten Themen zusammen mit dem Kind und schaffen in der Wohnumgebung des Kindes eine entsprechend religiös geprägte Atmosphäre. Vielfach lehren die Eltern ihre Kinder und übertragen das, was Sünde ist, was erlaubt ist, was gut und was schlecht ist, in verständliche Beispiele aus dem täglichen Leben. Da sie ihr geistig behindertes Kind genau kennen, können sie es leichter erreichen und den Moment am besten erkennen, wann es für das Gebet offen ist und wann sich das Gelernte gefestigt hat. Die mit der häuslichen Katechese richtig verbrachte Zeit ist für die Vertiefung und Sicherung der externen Katechese unerlässlich ${ }^{19}$.

Die aktive Teilnahme der Eltern an den katechetischen Stunden ist eine notwendige Bedingung für effektives katechetisches Einwirken, da sie dem geistig behinderten Kind die Möglichkeit zur Nachahmung und zur Identifikation verschafft, damit es in der entsprechenden Atmosphäre dazu angeregt wird, sich an den weiteren Beschäftigungen gerne zu beteiligen. Die Eltern und Pfleger sind dabei, wenn sich die behinderten Kinder untereinander begrüßen und verabschieden, wenn sie zusammen mit dem Katecheten den guten Jesus begrüßen und sich von ihm wieder verabschieden, wenn sie gemeinsam singen oder Bewegungsspiele ausführen, sie geben Hilfestellung beim Malen, Puzzeln, Basteln und bei anderen Tätigkeiten. Der Geistliche gibt die Botschaft an die Eltern weiter, die dadurch in einer spezifischen Art und Weise über die Thematik informiert werden, was und wann ihr Kind lernen wird, sie können die richtige Wortwahl, die Fachausdrücke und effektive Formen zur Vermittlung religiöser Inhalte von ihm übernehmen. Eine wichtige Aufgabe der Eltern besteht in der individuellen Arbeit mit

${ }^{19}$ Vgl. J. Stala, D. Jucha, Katechizacja osób upośledzonych umystowo, S. 335-336; D. Jucha, Sakrament Pokuty i I Komunia święta osób upośledzonych umystowo, in: Dzisiejszy katecheta. Stan aktualny $i$ wyzwania, Hrsg. J. Stala, Kraków 2002, S. 351-352. 
dem geistig behinderten Kind im familiären Umfeld, dazu gehören: die Ausführung der Aufgaben im Übungsheft des Kindes, das gemeinsame Gebet, das Trainieren von entsprechenden Verhaltensformen während der Hl. Messe in der Kirche und beim Empfang der Sakramente ${ }^{20}$.

Die Eltern und Pfleger sollen zusammen mit dem geistig behinderten Kind an der wöchentlichen Sonntagsmesse und einmal im Monat an einem besonderen Gottesdienst teilnehmen, nach dem die Kinder einen Rosenkranz, ein Büchlein, einen kleinen Anhänger, eine Kerze o. ä. erhalten. Sie sollen das Kind auf das richtige Verhalten während der Messe und beim Empfang der Hl. Kommunion hinweisen. Am wichtigsten ist es jedoch, dass sie auf vielfältige Weise versuchen in ihrem Kind den Wunsch zu wecken, Christus in sein Herz aufzunehmen. Mit der Hilfe des Geistlichen lehren die Eltern ihr Kind, die Schwierigkeiten zu überwinden, die sich aus seinen körperlichen Beeinträchtigungen ergeben und ihm dem Empfang der heiligen Kommunion erschweren. Falls das Kind Probleme mit der Speiseröhre hat, kann ihm der Priester auch eine kleinere Hostie geben, die Eltern müssten dafür Sorge tragen, dass diese im ganzen geschluckt wird. Sollten Teile davon jedoch zusammen mit Speichel wieder ausfließen, müssen die Eltern wissen, was in derartigen Fällen zu tun und wer zu informieren ist. Die nächsten Angehörigen sollen ihren Kindern die Angst vor dem Priester und den Anwesenden nehmen, sie sollen sie mit der neuen Situation vertraut machen, die der Empfang der Eucharistie darstellt. Bei der Vorbereitung des Kindes auf das Bußsakrament ist es dagegen wesentlich, dass die Eltern viel mit dem Kind sprechen und ihm auf sein Verständnisniveau übersetzen, was eine Sünde ist, wie man sich bessern kann und wie man sein Gewissen richtig erforscht ${ }^{21}$.

Hilfreich kann es darüber hinaus sein, Bildungsveranstaltungen zu besuchen, bei denen die Möglichkeit zum individuellen Gespräch mit dem Geistlichen über unterschiedlich geartete Probleme besteht, spezielle Exerzitien, klassische liturgische und Gottesdienste neuer Formen mitzufeiern oder Pilgerfahrten zu unternehmen. Für die Eltern ist es daneben ratsam,

${ }^{20} \mathrm{Vgl}$. H. Koselak, Katecheza specjalna jako dominująca forma duszpasterstwa osób upośledzonych umystowo, S. 107-108; K. M. Lausch, Katecheza przedkomunijna osób głębiej upośledzonych umysłowo, S. 23.

${ }^{21}$ Vgl. J. Tomczak, Btogosławić czy rozgrzeszać?, „Oligokatecheza” 1(3)/(2004), S. 21; E. Pawłowska, Pozwólcie dzieciom przychodzić do Mnie (Mk 10,14), „Oligokatecheza” 1(3)/(2004), S. 11; K. Lausch, Wychowanie religijne dzieci z niepetnosprawnościa intelektualna $w$ stopniu głębokim oraz ich przygotowanie do przyjęcia sakramentów świętych, S. 17; K. M. Lausch, Katecheza przedkomunijna osób głębiej upośledzonych umysłowo, S. 44. 
sich an Fachkonferenzen, an Tagen der Begegnung, am Gruppenaustausch sowie an Seminaren zu beteiligen, die sich mit dem Thema der geistigen Behinderung beschäftigen. Alle diese Initiativen der Seelsorge bringen den Eltern große Vorteile und lassen sie in ihrem eigenen Glauben wachsen ${ }^{22}$.

\section{Schlussfolgerung}

Zahlreiche Dokumente der Kirche, auch der Kirche Polens, greifen die Frage nach der Problematik und der Bedeutung der geistigen Behinderung ausdrücklich auf ${ }^{23}$. Der Durchbruch für die religiöse Erziehung von Kindern mit geistiger Behinderung gelang 1990 mit der Rückkehr des Religionsunterrichts an die Schulen. Erst ab dieser Zeit errang diese früher stark vernachlässigte Form der Katechese neue Möglichkeiten und Impulse. Die Religionserziehung erfordert eine überaus spezifische Vorbereitung, die nicht nur die intellektuelle Bildung betrifft sondern eine bestimmte Vorliebe für diese besondere Arbeit verlangt. Eine wesentliche Rolle spielen dabei die drei wichtigsten Lebensumfelder der religiösen Erziehung: die Pfarrgemeinde, die Familie und die Schule. Von großer Bedeutung können in diesem katechetischen Dienst die Materialien und Lehrbücher sein, die derzeit in stets wachsender Anzahl und verbesserter Ausarbeitung erscheinen.

\footnotetext{
${ }^{22}$ Vgl. J. Tomczak, Błogosławić czy rozgrzeszać?, S. 24; H. Koselak, Duszpastersko-wychowawcza działalność wobec osób niepetnosprawnych umystowo, S. 23.

${ }^{23}$ Vgl. J. Stala, Der Mensch als Person: Die bestimmende Grundlage für Johannes Paul II. in seinem Bild von der Familie, „The Person and the Challenges” 2 (2012) Nr. 2, S. 41-59; J. Stala, Godność człowieka niepetnosprawnego, in: Katecheza osób szczególnej troski. Stan aktualny. Propozycje na przyszłość, Hrsg. A. Kiciński, Kraków 2008, S. 11-22; J. M. Oszczepalińska, Problem integracji społecznej dzieci niepetnosprawnych intelektualnie w świetle badań własnych, Warszawa 2006; J. Kirenko, Oblicza niepetnosprawności, Lublin 2006; A. Krause, Człowiek niepetnosprawny wobec przeobrażeń społecznych, Kraków 2005; E. Osewska, Pomoc rodzinie $z$ osoba niepetnosprawna $w$ świetle polityki prorodzinnej Polski po roku 1999, in: Katecheza specjalna dzisiaj. Problemy i wyzwania, Hrsg. J. Stala, Kielce 2003, S. 119-131; B. Rozen, Potrzeby osób upośledzonych umystowo zwiąane z rozwojem osobowości spolecznej, in: Katecheza specjalna dzisiaj. Problemy $i$ wyzwania, Hrsg. J. Stala, Kielce 2003, S. 207-228; Diagnoza dla osób niepetnosprawnych, Hrsg. D. Lotz, K. Wenta, W. Seidler, Szczecin 2002; A. Twardowski, Sytuacja rodzin dzieci niepetnosprawnych, in: Dziecko niepetnosprawne $w$ rodzinie, Hrsg. I. Obuchowska, Warszawa 1999, S. 18-54; Dziecko niepetnosprawne, jego rodzina i edukacja, Hrsg. K. J. Zabłocki, Warszawa 1999; R. Kościelak, Funkcjonowanie psychospołeczne osób niepetnosprawnych umystowo, Warszawa 1996; A. Ostrowska, J. Sikorska, I. Sufin, Sytuacja ludzi niepetnosprawnych $w$ Polsce, Warszawa 1994.
} 


\section{Bibliography}

Borzyszkowska H., Izolacja społeczna rodzin majacych dziecko upośledzone umysłowo w stopniu lekkim, Gdańsk 1997.

Brzezinka Z., Katecheza specjalna. Katecheza osób w szczególnych sytuacjach, in: Katechetyka szczegółowa, Hrsg. J. Stala, Tarnów 2003, S. 293-305.

Diagnoza dla osób niepetnosprawnych, Hrsg. D. Lotz, K. Wenta, W. Seidler, Szczecin 2002.

Dziecko niepetnosprawne, jego rodzina i edukacja, Hrsg. K. J. Zabłocki, Warszawa 1999.

Edukacja uczniów z głębszym upośledzeniem umysłowym. Przewodnik dla nauczycieli, Hrsg. M. Orkisz, M. Piszczek, A. Smyczek, J. Szwiec, Warszawa 2000.

Etyczne i duchowe potrzeby osób niepetnosprawnych, Hrsg. R. Buchta, K. Sosna, Katowice 2007.

Katecheza specjalna dzisiaj. Problemy i wyzwania, Hrsg. J. Stala, Kielce 2003.

Kazanowski Z., Środowisko rodzinne młodzieży niepetnosprawnej intelektualnie w stopniu lekkim, Lublin 2003.

Kiciński A., Katecheza grup specjalnej troski, „Roczniki Teologiczne” (2003) Nr. 6, S. 121-137.

Kiciński A., Katecheza osób z niepetnosprawnością intelektualna, Lublin 2007.

Kielar A. M., Kiedy $w$ rodzinie przychodzi na świat dziecko niepetnosprawne, „Oligokatecheza” 1 (2003) Nr. 2, S. 6-12.

Kirenko J., Oblicza niepetnosprawności, Lublin 2006.

Kirenko J., Parchomiuk M., Edukacja i rehabilitacja osób z upośledzeniem umystowym, Lublin 2006.

Kornas-Biela D., Osoba niepetnosprawna i jej miejsce w społeczeństwie, Lublin 1988.

Kosacz M., Osoby o intelektualnej niepetnosprawności $w$ Kościele i społeczeństwie, „Katecheta” 45 (2001) Nr. 2, S. 43-48.

Koselak H., Wychowanie religijne osób niepetnosprawnych umystowo, „Horyzonty Wiary” (1993), S. 66-75.

Kościelak R., Funkcjonowanie psychospołeczne osób niepetnosprawnych umystowo, Warszawa 1996.

Krause A., Człowiek niepetnosprawny wobec przeobrażeń społecznych, Kraków 2005.

Kruk M., Relacje między rodzeństwem zdrowym i niepetnosprawnym $w$ rodzinie, „Światło i Cienie" (1996) Nr. 2, S. 4-8.

Lausch K. i K., Stów kilka o wychowaniu religijnym dzieci i młodzieży z głęboka niepetnosprawnościa intelektualna, in: Katecheza specjalna dzisiaj. Problemy $i$ wyzwania, Hrsg. J. Stala, Kielce 2003, S. 169-185.

Lausch K. M., Teoretyczne podstawy katechizacji osób głębiej upośledzonych umysłowo, Warszawa 1987.

Osewska E., Pomoc rodzinie z osoba niepetnosprawna w świetle polityki prorodzinnej Polski po roku 1999, in: Katecheza specjalna dzisiaj. Problemy $i$ wyzwania, Hrsg. J. Stala, Kielce 2003, S. 119-131.

Ostrowska A., Sikorska J., Sufin I., Sytuacja ludzi niepetnosprawnych w Polsce, Warszawa 1994. 
Oszczepalińska J. M., Problem integracji społecznej dzieci niepelnosprawnych intelektualnie w świetle badań wtasnych, Warszawa 2006.

Rozen B., Edukacja religijna osób z niepetnosprawnościa intelektualną. Studium pedagogiczno-religijne, Olsztyn 2008.

Sidor B., Trudności przė̇ywane przez rodzine dziecka z niepetnosprawnościa umysłowa, in: Rodzina: źródło życia i szkoła miłości, Hrsg. D. Kornas-Biela, Lublin 2000, S. 393-405.

Sosna K., Przygotowanie do Komunii Świętej osób niepetnosprawnych umysłowo w świetle dekretu Quam singulari, in: Eucharystia - pokuta i pojednanie w katechezie, Hrsg. J. Stala, Kielce 2007, S. 235-244.

Stala J., Der Mensch als Person: Die bestimmende Grundlage für Johannes Paul II. in seinem Bild von der Familie, „The Person and the Challenges” 2 (2012) Nr. 2, S. 41-59.

Stala J., Godność czlowieka niepetnosprawnego, in: Katecheza osób szczególnej troski. Stan aktualny. Propozycje na przyszłość, Hrsg. A. Kiciński, Kraków 2008, S. 11-22.

Stala J., Jucha D., Katechizacja osób upośledzonych umysłowo, in: Katechetyka szczegółowa, Hrsg. J. Stala, Tarnów 2003, S. 306-350.

Stala J., Katecheza specjalna realizacją Bożego miłosierdzia , „Edukacja. Teologia i Dialog” (2004), T. 1: Miłosierdzie jako wartość w języku współczesnej edukacji, Hrsg. R. Niparko, J. Skrzypczak, S. 189-200.

Stala J., Katecheza specjalna wyrazem troski o każdego czlowieka w świetle dokumentów synodalnych Kościoła w Polsce po 1980 roku, in: Katecheza specjalna dzisiaj. Problemy $i$ wyzwania, Hrsg. J. Stala, Kielce 2003, S. 55-66.

Stala J., Rodzina wobec niepetnosprawności intelektualnej dziecka. Obawy i nadzieje, in: Etyczne i duchowe potrzeby osób niepetnosprawnych, Hrsg. R. Buchta, K. Sosna, Katowice 2007, S. 30-39.

Wyczesany J., Pedagogika upośledzonych umystowo, Kraków 1999.

Żyta A., Edukacja osób z głębsza niepetnosprawnościa intelektualna w Polsce-przeszłość, teraźniejszość i przyszłość, in: Wielowymiarowość edukacji osób z niepetnosprawnościa, Hrsg. C. Kosakowski, C. Rogowski, Olsztyn 2005, S. 169-175. 